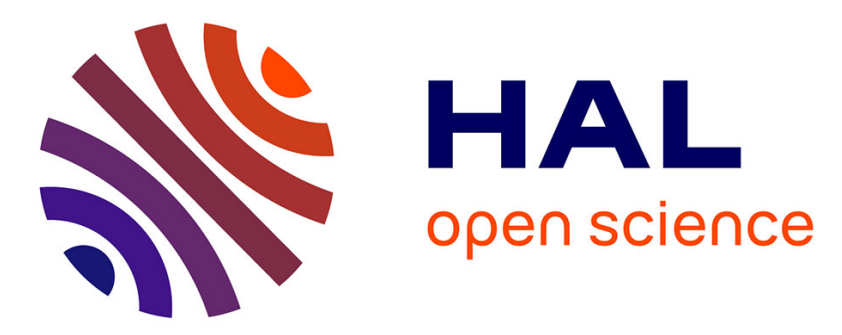

\title{
A Study of CVD of Gallium Nitride Films by In Situ Gas-Phase UV Spectroscopy
}

S. Alexandrov, A. Kovalgin, D. Krasovitskiy

\section{To cite this version:}

S. Alexandrov, A. Kovalgin, D. Krasovitskiy. A Study of CVD of Gallium Nitride Films by In Situ Gas-Phase UV Spectroscopy. Journal de Physique IV Proceedings, 1995, 05 (C5), pp.C5-183-C5-190. 10.1051/jphyscol:1995520 . jpa-00253845

\section{HAL Id: jpa-00253845 https://hal.science/jpa-00253845}

Submitted on 1 Jan 1995

HAL is a multi-disciplinary open access archive for the deposit and dissemination of scientific research documents, whether they are published or not. The documents may come from teaching and research institutions in France or abroad, or from public or private research centers.
L'archive ouverte pluridisciplinaire HAL, est destinée au dépôt et à la diffusion de documents scientifiques de niveau recherche, publiés ou non, émanant des établissements d'enseignement et de recherche français ou étrangers, des laboratoires publics ou privés. 


\title{
A Study of CVD of Gallium Nitride Films by In Situ Gas-Phase UV Spectroscopy
}

\author{
S.E. Alexandrov, A.Y. Kovalgin and D.M. Krasovitskiy
}

Department of Electronic Materials Technology, St.-Petersburg State Technical University, Polytechnical Str. 29, St.-Petersburg, 195 251, Russia

\begin{abstract}
A bstract. Direct "in situ" UV spectroscopic analysis of the gas phase was performed during chemical vapour deposition of gallium nitride films based on pyrolysis of $\mathrm{GaCl}_{3} \mathrm{NH}_{3}$ complexes. The most probable mechanism of film formation is proposed on the basis of the experimental results obtained.
\end{abstract}

\section{INTRODUCTION}

Wide band gap gallium nitride is attracting considerable interest because of its use in the preparation of electronic devices, such as light emitting diodes and laser diodes performing in the blue and UV region [1,2]. A number of different types of deposition techniques are used for forming gallium nitride layers, but the most widespread method is chemical vapour deposition from gallium halogenides and ammonia because this technique provides deposition of high quality $\mathrm{GaN}$ layers with relatively high growth rates $[3,4]$. However the mechanism of deposition is still not completely clear in spite of the considerable research, which has been carried out. An improved understanding of the process chemistry is desirable for improving the reproducibility of deposition and film quality.

The results of the experimental study and thermodynamical calculation $[5,6]$ show that the gas phase formed during the process of CVD of gallium nitride films in the Ga-Cl-N-H System has a complicated composition, probably because of the accurrence of several homogeneous and heterogeneous reactions. The summary growth rate as well as the deposition mechanism are likely to be determined by the relative concentrations of species being formed in the gas phase. In this connection, it is clear that the available information on the actual composition of the gas phase in the deposition zone, obtained directly during the CVD process, is very important for a better understanding of the regularity of GaN film growth.

The main purpose of this paper is to report new results from a study of CVD of gallium nitride films based on pyrolysis of the complex of gallium trichloride with ammonia, $\mathrm{GaCl}_{3} \mathrm{NH}_{3}$ In order to minimise any possible influence on the process chemistry, and also because some components, whose formation is to be expected in the Ga-Cl-N-H System, have the absorption bands in the UV region [6-9], direct "in situ" ultraviolet spectroscopic analysis of the gas phase during CVD was carried out.

\section{EXPERIMENTAL}

A schematic diagram of the experimental apparatus used in this study is shown in Fig. 1. A special two zone hot wall model reactor with quartz windows, which permitted transmittance spectra in the region (200-350) $\mathrm{nm}$, was placed between the source of UV light (deuterium lamp, $30 \mathrm{~W}$ ) and the monochromator. The light was directed through the reaction zone. The dispersion of the monochromator lattice at the width of input aperture of $0.05 \mathrm{~mm}$ does not exceed the value of $0.2 \mathrm{~nm}$ in the region $(200-350) \mathrm{nm}$. The intensity of the 


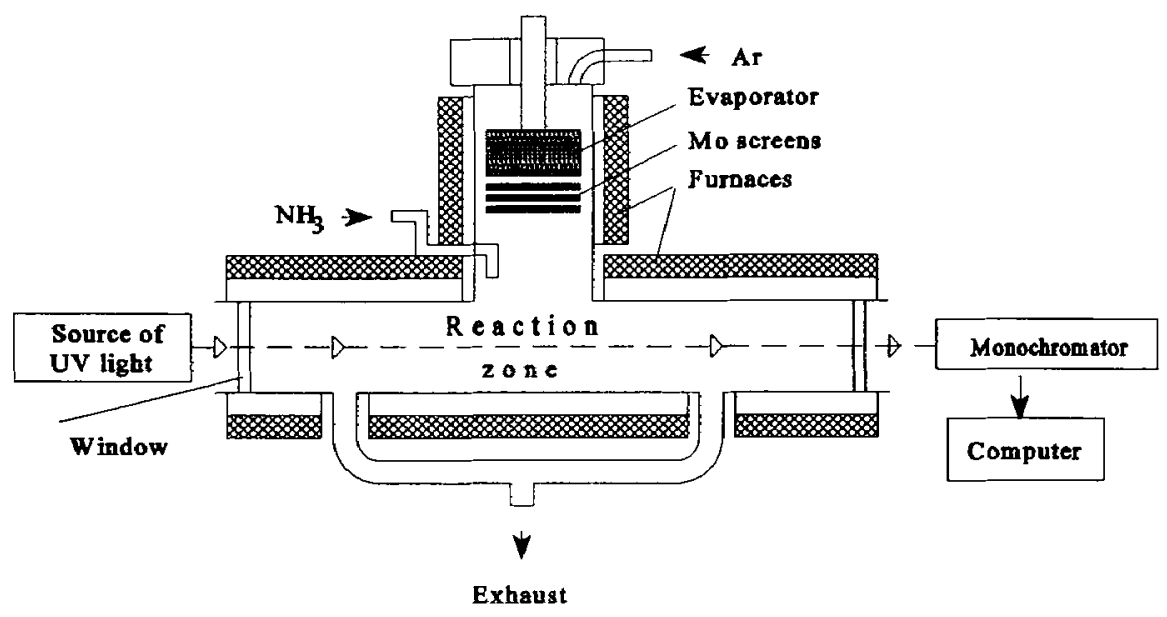

Figure1: Schematic diagram of the experimental apparatus

monochromatic light was measured with a FEU-100 photomultiplier. Transmittance spectra of the gas phase, obtained during pyrolysis of $\mathrm{GaCl}_{3} \mathrm{NH}_{3}$ at atmospheric pressure in the temperature range 300-1100 ${ }^{\circ} \mathrm{C}$, were recorded in the region of (200-350) $\mathrm{nm}$.

The vapour of precursor $\left(\mathrm{GaCl}_{3} \mathrm{NH}_{3}\right)$ from the evaporator was delivered with carrier gas (electronic grade argon) to the reaction zone. To prevent overheating of the evaporator at high temperatures in the reaction zone, a system of Mo screens was placed between the evaporation zone and the reaction zone. These zones were separately heated with resistance furnaces, and their temperatures were measured with the thermocouples. The construction of the model reactor allows the introduction of additional reagents into the reaction zone.

The complex of gallium trichloride with ammonia, $\mathrm{GaCl}_{3} \mathrm{NH}_{3}$, was previously synthesised from gallium $(99.99 \%)$ and $\mathrm{NH}_{4} \mathrm{Cl}$ (electronic grade). The partial pressure of the initial complex can be changed in the region $20-3000 \mathrm{~Pa}$ by varying the evaporation temperature.

\section{EXPERIMENTAL RESULTS AND DISCUSSION}

Typical UV spectra of the gas phase, which were formed during pyrolysis at different temperatures, are shown in Figures $2(a, b, c)$. The partial pressure of $\mathrm{GaCl}_{3} \mathrm{NH}_{3}$ was about $360 \mathrm{~Pa}$ in all these experiments. One can see that a system of absorption bands in the region (200-230) nm was observed in all spectra obtained at the reaction zone temperatures of $300-600^{\circ} \mathrm{C}$. Information on the position of the maxima of the above mentioned absorption bands is presented in the Table 1 . Also in this table one can find data on the absorption bands of pure ammonia, obtained at the same temperature.

Table 1. The positions of the absorption band maxima in the region $200-300 \mathrm{~nm}$.

\begin{tabular}{|c|c|c|c|c|c|c|c|}
\hline Conditions & \multicolumn{4}{|c|}{ Wavelengths corresponding to the maxima observed, $\mathrm{nm}$} \\
\hline Pyrolysis $\mathrm{GaCl}_{3} \cdot \mathrm{NH}_{3}, 350^{\circ} \mathrm{C}$ & 202.0 & 205.5 & 209.5 & 213.5 & 217.5 & 222.0 & 225.0 \\
\hline Gaseous ammonia, $350^{\circ} \mathrm{C}$ & 202.0 & 205.0 & 209.0 & 213.0 & 217.5 & 221.5 & 225.0 \\
\hline
\end{tabular}

The difference in the position of maxima does not exceed a value of $0.5 \mathrm{~nm}$, which was the step of discreteness of wavelength scale used in this work. Thus, this coincidence as well as the general appearance of the obtained spectrum, which is analogous to that previously published [8], allows us to conclude that the 

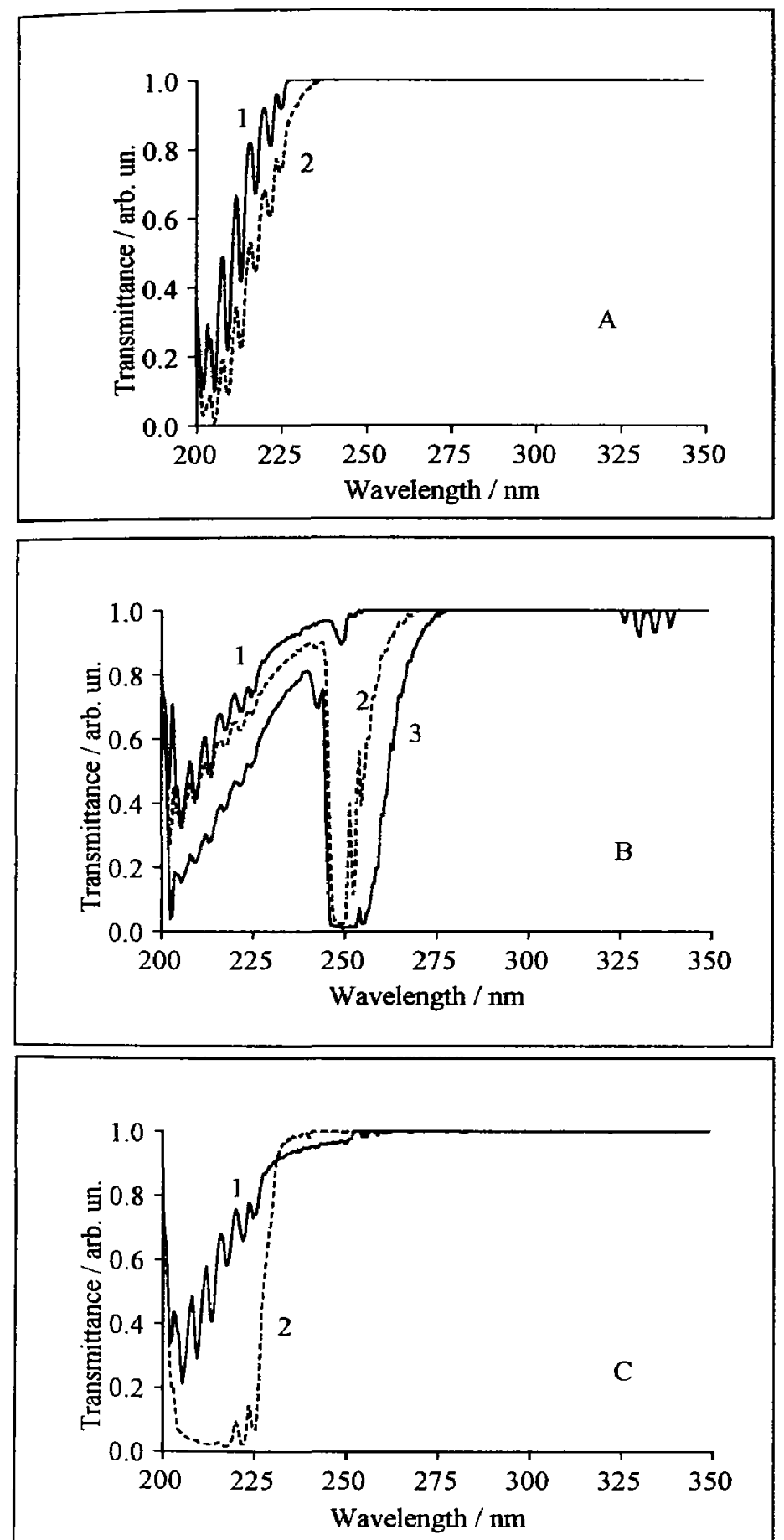

Figure 2: The typical UV spectra of the gas phase at different temperatures ( ${ }^{\circ}$ ) : al -350; a2-500; bl-600; b2-750; b3-900; cl-350 for $\mathrm{GaCl}_{3} \mathrm{NH}_{5}-\mathrm{Ar}$ System; c2-350 for $\mathrm{NH}_{3}$-Ar System. above mentioned system corresponds to the electronic transition $\widetilde{\mathrm{X}}_{1} \mathrm{~A}_{1}^{\prime}-\widetilde{\mathrm{A}}_{1} \mathrm{~A}_{2}^{\prime \prime}$ in $\mathrm{NH}_{3}$ molecule.

Also the steeper decrease of transmittance, starting from $260 \mathrm{~nm}$ and then increasing to lower wavelengths till the consolidation with the absorption bands of ammonia, was observed in the region (230-260) $\mathrm{nm}$. The results of analysis of the transmittance spectra of pure ammonia show that the long-wave boundary of its absorption band system is very sharp: eventhough the absorption in the region (200-230) nm was high, the transmittance of a gas phase of pure ammonia goes to 1.0 at about $230 \mathrm{~nm}$ (Fig.2c,curve 2). Therefore the fall off in the transmittance in the region (230300) $\mathrm{nm}$ is caused by a broad absorption band with the maximum at $\lambda<230 \mathrm{~nm}$, belonging to a different compound. Gallium trichloride is the most probable of the above mentioned compounds, because it is known that its UV spectrum obtained in the temperature range $150-600^{\circ} \mathrm{C}$ has a broad absorption band with the maximum at $\lambda<200 \mathrm{~nm}[7]$. Thus it was found that molecules of $\mathrm{NH}_{3}$ and $\mathrm{GaCl}_{3}$ are present in the gas phase in the pyrolysis temperature region of about $300-600^{\circ} \mathrm{C}$.

In the temperature region $600-700{ }^{\circ} \mathrm{C}$ an absorption band with a maximum at 249 nm (Fig.2b, curve 1) was found. Analysis of the spectrometric data shows that this band corresponds to the electronic transition $C^{\prime} \Pi-X^{\prime} \Sigma^{+}$in the molecules of $\mathrm{GaCl}$ [9]. This agrees well with the previously published data $[7,10]$. As the temperature in the reaction zone increases, there is a marked increase in the intensity of this band. Also additional discrete absorption bands appeared in the region of higher wavelengths. The results of calculations (see table 2), performed using data from [9], show that the structure of the absorption band with the maximum at $249 \mathrm{~nm}$ corresponds to electronicvibrational transitions $v_{0,0}, v_{0,1}$ and $v_{0,2}$ between electronic states $\mathrm{X}^{\prime} \Sigma^{+}$(ground, $\left.v^{\prime \prime}=0,1,2\right)$ and $C^{\prime} \Pi$ (excited, $v^{\prime}=0$ ) in $\mathrm{GaCl}$ molecule. Furthermore an increase of temperature in this region causes an 
increase in the spectral width of ammonia bands, probably because of the breadth of vibrational levels of the $\mathrm{NH}_{3}$ molecule.

Table 2. The electronic-vibrational transitions in the $\mathrm{GaCl}$ molecule.

\begin{tabular}{|c|c|c|c|c|c|c|c|c|}
\hline Electronic & \multicolumn{8}{|c|}{ Absorption band maxima, calculated and observed, $\mathbf{n m}$} \\
\hline \multirow[t]{3}{*}{$C^{\prime} \Pi-X \Sigma^{+}$} & \multirow{2}{*}{$\begin{array}{l}\text { Calculation } \\
\text { with data } \\
\text { from [9] }\end{array}$} & $v_{0,0}$ & $v_{0,1}$ & $v_{0,2}$ & $v_{0,3}$ & \multicolumn{2}{|c|}{............. } & $v_{7,0}$ \\
\hline & & 249.0 & 251.0 & 253.0 & 256.0 & \multicolumn{2}{|c|}{............ } & 244.0 \\
\hline & $\begin{array}{l}\text { Observed } \\
\text { in this work }\end{array}$ & 249.0 & 252.0 & 254.0 & & \multicolumn{2}{|c|}{............ } & 243.5 \\
\hline \multirow[t]{4}{*}{$\mathrm{B}^{3} \Pi_{1}-\mathrm{X}^{\prime} \Sigma^{+}$} & \multirow{2}{*}{$\begin{array}{l}\text { Calculation } \\
\text { with data } \\
\text { from [9] }\end{array}$} & $v_{3,0}$ & $v_{2,0}$ & $v_{1,0}$ & $v_{0,0}$ & $v_{0,1}$ & $v_{02}$ & $v_{0,3}$ \\
\hline & & 322.0 & 326.0 & 330.0 & 334.0 & 338.0 & 343.0 & 347.0 \\
\hline & From [7] & 321.0 & 325.0 & 329.0 & 333.0 & 337.0 & 341.0 & 345.0 \\
\hline & $\begin{array}{l}\text { Observed in } \\
\text { this work }\end{array}$ & 322.5 & 326.0 & 330.0 & 334.0 & 339.0 & 343.0 & 347.0 \\
\hline
\end{tabular}

At higher temperatures $\left(>800^{\circ} \mathrm{C}\right)$ a new system of adsorption bands appeared in the region (320-350) $\mathrm{nm}$ (see Fig.2b, curve 3). It corresponds to the electronic transition $\mathrm{B}^{3} \Pi_{1}^{\leftrightarrow} \mathrm{X}^{\vee} \Sigma^{+}$of the GaCl molecule. Concurrently with this system, a separate absorption band at $243 \mathrm{~nm}$, corresponding to $C^{\prime} \Pi-X^{\prime} \Sigma^{+}$electronic transitions of $\mathrm{GaCl}$ molecules between $v^{\prime \prime}=0$ and $\nu^{\prime}=7$ vibrational levels was found. This effect seems to be the result of the increasing population density of upper vibrational levels of the $C^{\prime} \Pi$ electronic state of $\mathrm{GaCl}$ molecule.

As the temperature in the reaction zone increases higher than $800^{\circ} \mathrm{C}$, the partial merging of discrete bands, belonging to the electron-vibrational system of $\mathrm{NH}_{3}(200-300 \mathrm{~nm})$ and $\mathrm{GaCl}(240-260 \mathrm{~nm})$ was observed. This caused a considerable increase in intensity of absorption in the above mentioned regions, because of the effect of temperature on the breadth of vibrational levels. When the temperature in the reaction zone was higher than $850^{\circ} \mathrm{C}$, the intensity of the absorption band at $249 \mathrm{~nm}$ was so high that transmittance in the region $250-270$ $\mathrm{nm}$ was almost zero.

Thus, analysis of transmittance spectra of the gas phase obtained during pyrolysis of $\mathrm{GaCl}_{3} \mathrm{NH}_{3}$ demonstrates that molecules of $\mathrm{NH}_{3} \mathrm{GaCl}_{3}$ and $\mathrm{GaCl}$ are present in the reaction gas mixture, and their relative concentrations are dependent on the temperature of pyrolysis.

To examine trends in the variation of concentrations of these compounds with temperature in the reaction zone, the integral absorption coefficient $\mathrm{K}$ was calculated as follows:

$$
\mathrm{K}=\frac{1}{\ell} \int_{\lambda 2}^{\lambda 1} \mathrm{D}(\lambda) \mathrm{d} \lambda
$$

where $\mathrm{K}$ - an area under curve $\mathrm{K}=\mathrm{f}(\lambda), \mathrm{cm}^{-1} ; \ell$ - the distance between optical windows of reaction chamber, $\mathrm{cm} ; \mathrm{D}(\lambda)=-\ln [\mathrm{T}(\lambda)]$ - optical density; $\lambda_{1}, \lambda_{2}$ - the boundaries of integration for each system of absorption bands, $\mathrm{nm}$. The integral absorption coefficient has the same dimensions as a conventional absorption 


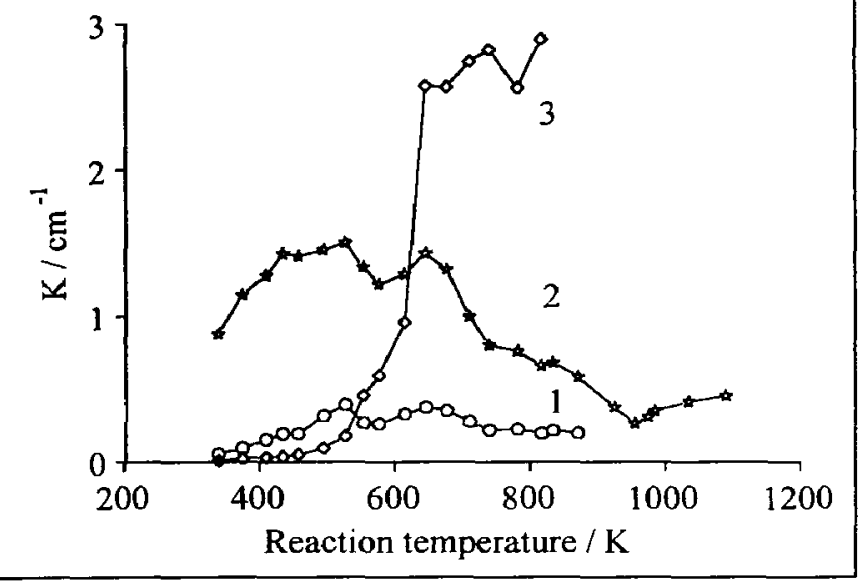

Figure 3: Dependence of the integral absorption coefficient $\mathrm{K}$ for some components of the gas phase on temperature; $1-\mathrm{GaCl}_{3} ; 2-\mathrm{NH}_{3} ; 3-\mathrm{GaCl}$; Partial pressure of $\mathrm{GaCl}_{3} \mathrm{NH}_{3}$ complex $-360 \mathrm{~Pa}$. coefficient, but it characterises absorption over a range of wavelengths in contrast to a conventional coefficient, which determines absorption at a specific $\lambda$. This provides the possibility for estimating more reliably the value of $K$, which is proportional to the concentration of the absorbing species. The integral absorption coefficient $\mathrm{K}$ for $\mathrm{GaCl}_{3}$ was calculated in the region $235\left(\lambda_{1}\right)-245\left(\lambda_{2}\right) \mathrm{nm}$, where there is no an overlap of the absorption bands corresponding to $\mathrm{GaCl}_{3}$ and $\mathrm{NH}_{3}$ (see Fig 2c)

Typical dependence of $K$ for some species, found in the gas phase, on temperature in the reaction zone are presented in Fig. 3. It should be noted that variation of the partial pressure of $\mathrm{GaCl}_{3} \mathrm{NH}_{3}$ did not cause changes in the character of this dependence. As one can see an increase in pyrolysis temperature in the region $300-500^{\circ} \mathrm{C}$ causes an increase

in concentrations of $\mathrm{NH}_{3}$ and $\mathrm{GaCl}_{3}$ in the gas phase. The values of the partial pressures of ammonia, calculated from the results of experiments with gas mixtures containing known amounts of $\mathrm{NH}_{3}$ were in the region 10-25 $\mathrm{Pa}$. It is most probable, that the presence of $\mathrm{NH}_{3}$ and $\mathrm{GaCl}_{3}$ in the gas phase is caused by partial dissociation of $\mathrm{GaCl}_{3} \mathrm{NH}_{3}$ complex via the following reaction:

$$
\mathrm{GaCl}_{3} \cdot \mathrm{NH}_{3} \rightleftharpoons \mathrm{GaCl}_{3}+\mathrm{NH}_{3}
$$

This reaction is thermodynamically probable in the temperature region $300-500{ }^{\circ} \mathrm{C}[12]$, whereas decomposition of the complex via the reaction (2) is impossible at such low temperatures.

$$
\mathrm{GaCl}_{3} \mathrm{NH}_{3} \rightarrow \mathrm{GaN}+3 \mathrm{HCl}
$$

Calculations made on the basis of real values of the partial pressure of ammonia, show that the values of the degree of dissociation of the initial complex on $\mathrm{GaCl}_{3}$ and $\mathrm{NH}_{3}$ do not exceed $5 \%$ at temperatures of about 440 ${ }^{\circ} \mathrm{C}$. This agrees well with the results of thermodynamical calculations and the data from [12]. Thus, it was found that at pyrolysis temperatures lower than $500^{\circ} \mathrm{C}$, the gas phase mainly consisted of the initial $\mathrm{GaCl}_{3} \mathrm{NH}_{3}$ complex.

At temperatures of pyrolysis above $500^{\circ} \mathrm{C}$, the reaction (2) is possible and leads to a decrease in the concentrations of $\mathrm{GaCl}_{3}$ and $\mathrm{NH}_{3}$ in the gas phase (Fig.3), in spite of the shift of equilibrium of the reaction (1) to form more reaction products at the higher temperatures. Concurrently with the beginning of the reaction (2), gallium monochloride appeared in the gas phase (Fig.3), whereupon its concentration increased with pyrolysis temperature. In connection with the accumulation of $\mathrm{HCl}$ in the gas phase because of the reaction (2), the most probable reason for formation of $\mathrm{GaCl}$ vapour in the deposition zone is reaction of deposited gallium nitride films with $\mathrm{HCl}$ vapours:

$$
\mathrm{GaN}+\mathrm{HCl} \rightarrow \mathrm{GaCl}+1 / 2 \mathrm{H}_{2}+1 / 2 \mathrm{~N}_{2}
$$



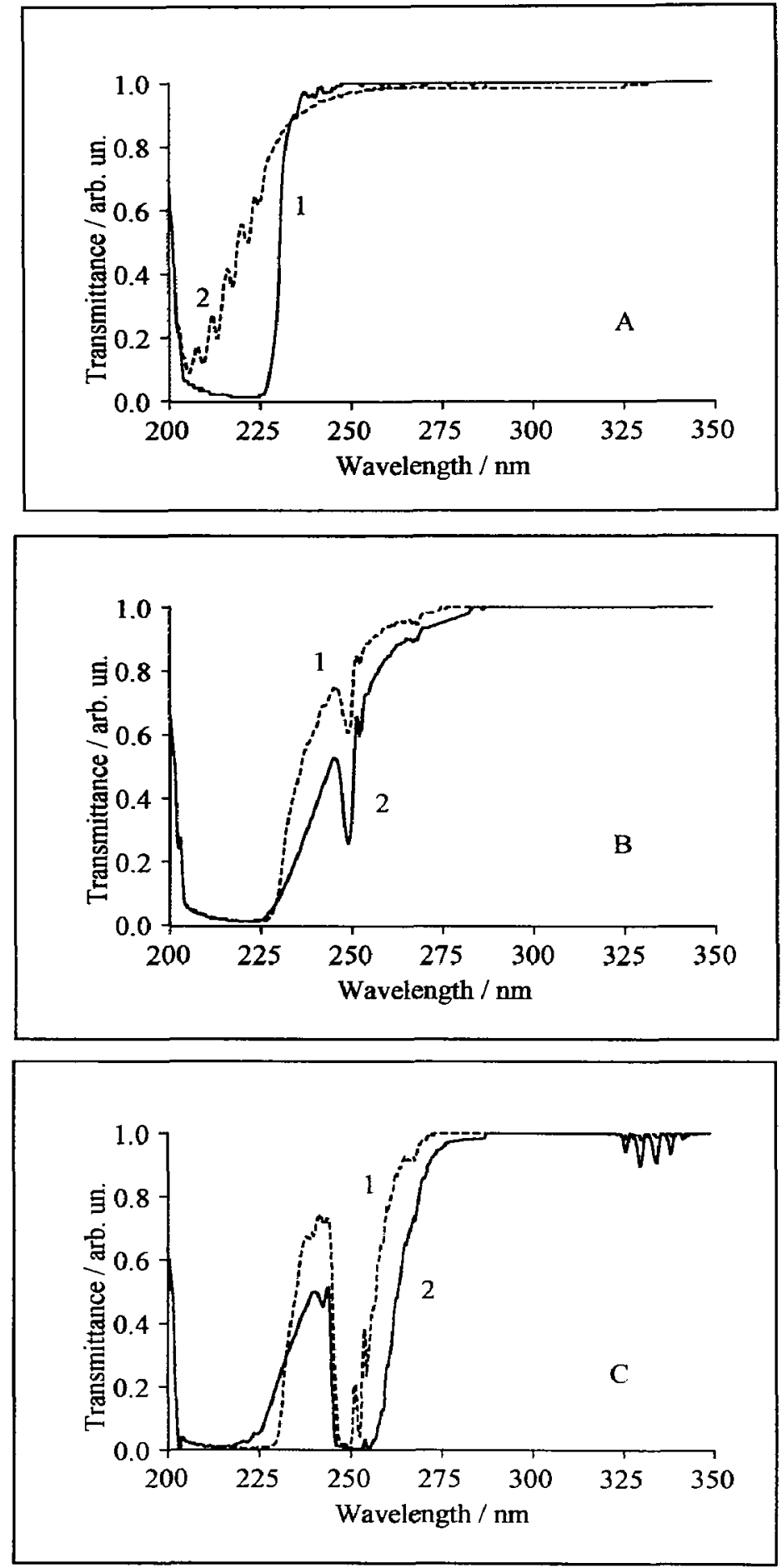

Figure 4: The typical UV spectra of the gas phase, being formed during pyrolysis with(1) and without(2) introduction of $\mathrm{NH}_{3}$ at different temperatures ( $\left.{ }^{\circ} \mathrm{C}\right)$ : $a-350 ; b-700 ; c-850$.
This is confirmed by the results of thermodynamical calculations, indicating a high thermodynamical probability of the reaction (3) under research conditions, as well as under the special experiment conditions, when $\mathrm{HCl}$ gas is passed through a model reactor previously covered with GaN films. Hydrogen chloride for these experiments was obtained as a product of $\mathrm{GaCl}_{3} \mathrm{NH}_{3}$ pyrolysis, which was carried out in an additional reaction chamber, tandem placed in the gas line before the main reactor. This provided a $\mathrm{HCl}$ partial pressure almost equal to that during deposition of $\mathrm{GaN}$ by pyrolysis of $\mathrm{GaCl}_{3} \mathrm{NH}_{3}$ complex. Appearance of the absorption band at $249 \mathrm{~nm}$ was detected in the spectra of the gas phase obtained even at about $500^{\circ} \mathrm{C}$, and the intensity of this band increased with temperature. Thus, this direct experiment confirms the occurrence of the reaction (3) under the conditions being studied, and also points to the fact that the reaction (2) has a irreversible character, because the absorption bands, corresponding to $\mathrm{NH}_{3}$ and $\mathrm{GaCl}_{3}$, were not found in all the spectra obtained. They would have been expected if there had been $\mathrm{GaCl}_{3} \mathrm{NH}_{3}$ complexes in the gas phase.

On the basis of the obtained results one can suggest that chemical vapour deposition of $\mathrm{GaN}$, based on pyrolysis of $\mathrm{GaCl}_{3} \mathrm{NH}_{3}$ is probably determined by competition of the irreversible reactions (2) and (3). The growth of GaN films occurs only because of the higher rate of the reaction (2) in comparison with that of the reaction (3) under the same conditions.

Furthermore one can suggest that the growth of $\mathrm{GaN}$ at temperature above 650 ${ }^{\circ} \mathrm{C}$ occurs with direct participation of gallium halogenides and ammonia, because of almost complete dissociation of the initial complex via the reaction (1). In this connection it is clear that $\mathrm{NH}_{3}$, being present in the gas phase, must play an important role in the deposition process. To clarify this, a set of experiments with the introduction of additional gaseous ammonia into the reaction zone was carried 
out.

The typical UV spectra of the gas phase, being formed during pyrolysis at different temperatures with and without introduction of ammonia, are shown in Figures $4 a, b, c$. Analysis of these spectra shows that introduction of $\mathrm{NH}_{3}$ leads to a decrease in the concentration of $\mathrm{GaCl}_{3}$ in the gas phase at the pyrolysis temperatures being studied. This is indicated by an increase of the transmittance in the region $230-245 \mathrm{~nm}$, and this was the only effect observed at pyrolysis temperature in the region 300-500 $\mathrm{C}$. At such low temperatures, when decomposition of $\mathrm{GaCl}_{3} \mathrm{NH}_{3}$ via the reaction (2) is impossible, and only the reaction (1) occurs in the gas phase, the influence of $\mathrm{NH}_{3}$ probably lies in the shift of the equilibrium of the reaction (1) to form $\mathrm{GaCl}_{3} \mathrm{NH}_{3}$ complex.

At temperatures of pyrolysis above $500{ }^{\circ} \mathrm{C}$, when deposition of $\mathrm{GaN}$ layers occurred, introduction of ammonia also caused a decrease in the concentration of $\mathrm{GaCl}$ in the gas phase. This is indicated by a decrease of the intensities of absorption bands in the regions $245-270 \mathrm{~nm}$ and $320-350 \mathrm{~nm}$. Together with the above mentioned spectral effects, introduction of $\mathrm{NH}_{3}$ into the reactor caused a large increase in the deposition rate of $\mathrm{GaN}$ at all temperatures being studied (for example $1,5 \mu \mathrm{m} / \mathrm{h}$ - without $\mathrm{NH}_{3}$ and $11.5 \mu \mathrm{m} / \mathrm{h}$ with introduction of $\mathrm{NH}_{3}$; the other deposition conditions were the same: Tdep $=600^{\circ} \mathrm{C}$, partial pressure of complex - $200 \mathrm{~Pa}$ ).

An increase of deposition rate of GaN, observed in these experiments, does not contradict the possible growth of complex concentration due to the quenching of its dissociation in the gas phase, however the results of special experiments on GaN deposition, performed in this study, show that the maximum increase in deposition rate because of the complete quenching of the reaction (1) is expected to be increased by a factor of about five at $600^{\circ} \mathrm{C}$, and the observed increase was more than one order of magnitude higher. Also the effect of a decrease of $\mathrm{GaCl}$ concentration can not be included into a model of the deposition process, based only on the occurrence of the reactions (1)-(3). In fact, the quenching of the reaction (1) must lead to an acceleration of the reactions (2) and (3), and therefore to the growth of $\mathrm{GaCl}$ concentration in the gas phase. These considerations allow us to suggest the occurrence of the following reactions in the deposition zone:

$$
\begin{aligned}
& \mathrm{GaCl}+\mathrm{NH}_{3} \rightarrow \mathrm{GaN}+\mathrm{H}_{2}+\mathrm{HCl} \\
& \mathrm{GaCl}_{3}+\mathrm{NH}_{3} \rightarrow \mathrm{GaN}+3 \mathrm{HCl}
\end{aligned}
$$

Both these reactions are thermodynamically probable under conditions realized in these experiments However, the occurrence of the reaction (5) is likely to be accompanied by a sharper increase in $\mathrm{HCl}$ concentration in the gas phase. This must lead to an acceleration of the reaction (2) and therefore to an increase in concentration of $\mathrm{GaCl}$, which is in contrast with the experimental results obtained. This inconsistency can be overcome if an interaction of the resulting $\mathrm{GaCl}$ with ammonia via the reaction (4) is suggested. These considerations show that the occurrence of the reaction (4) seems to be responsible for the acceleration of the $\mathrm{GaN}$ deposition process, although it is not correct to exclude completely the probability of the simultaneous occurrence of the reaction (5). This conclusion agrees well with the results of a mass-spectrometric study of the composition of the gas phase during CVD of GaN layers in the $\mathrm{GaCl}-\mathrm{NH}_{3}$ System [5,6]. It was shown that the reaction (4) is fairly fast, and probably "it is the biggest contributor to the deposition of GaN". Furthermore, the deposition rate of $\mathrm{GaN}$ layers in the $\mathrm{GaCl}-\mathrm{NH}_{3}$ System can reach the value of about $70 \mu \mathrm{m} / \mathrm{h}[12]$, which is more than one order of magnitude higher than the typical value of gallium nitride deposition rates by pyrolysis of $\mathrm{GaCl}_{3} \mathrm{NH}_{3}$ complex. It is interesting to note that at the same time hypothetical limitations of growth rate because of slow diffusion of gallium monochloride through the boundary layer and over the reaction surface are impossible in this case. Vapour of $\mathrm{GaCl}$ is mainly formed due to etching of the growing $\mathrm{GaN}$ layers with gaseous $\mathrm{HCl}$, and therefore the source of gallium monochloride is located on the reaction surface.

\section{CONCLUSIONS}

To summarise, for the mechanism of deposition, we suggest that chemical vapour deposition of gallium nitride layers, based on pyrolysis of $\mathrm{GaCl}_{3} \mathrm{NH}_{3}$ complex, is determined by competition of the irreversible reactions 
(2) and (3). The growth of GaN films occurs only because of the higher rate of the reaction (2) in comparison with that of the reaction (3) under the same conditions. At temperatures of pyrolysis higher than about $650 \mathrm{C}$ formation of gallium nitride occurs with direct participation of gallium halogenides and ammonia as the initial complex $\mathrm{GaCl}_{3} \mathrm{NH}_{3}$ is completely dissociated according to the reaction (1). The reaction between gallium monochloride and ammonia is the main reaction determining the film growth at these temperatures. Introduction of an additional amount of ammonia into the reactor caused a large increase in the deposition rate of gallium nitride due to interaction of ammonia with gallium monochloride, mainly formed by etching of the growing $\mathrm{GaN}$ layers with $\mathrm{HCl}$ vapours.

\section{References}

[1] Hovel H.J. and CuomoJ.J., Appl. Phys. Lett. 20(1972) 71-73.

[2] Chu T.L. J. Electrochem. Soc. 118(1971) 1200-1203.

[3] Jacob G., Madar R., Hallais J. J. Mat. Res. Bull. 11(1976) 324-326.

[4] Furukawa Y. Jap. J. Appl. Phys. 23(1984) 376-377.

[5] Ban V.S. J. Cryst. Growth 17(1972) 19-30.

[6] Ban V.S. J. Electrochem. Soc. 119(1972)761-765.

[7] Kuniya Y., Hosaka M. J. Cryst. Growth 28(1975) 385-393.

[8] Sugii T., Ito T., Ishikawa H. Ext. Abstr. of 16th Conf. on Sol. St. Dev. \& Mat., Kobe 1984,pp.433-436.

[9] Huber K.P., Herzberg G. Molecular spectra and molecular structure. v4. Constants of diatomic molecules (New York, Van Nostrand Reimond, 1979), 716p.

[10] Karlicek R.F. and Bloemeke A. J. Cryst. Growth 73(1985) 364-368.

[11] Zhilaev Y.V., Kulikov A.Y. Cryst. Prop. Prep. 32-34 Pt2(1991) 450-452.

[12] Naniwae K., Itoh S., Amano H., et al. J. Cryst. Growth 99(1990) 381-384. 